Article

\title{
Features and Socio-Economic Sustainability of Traditional Chestnut Forestry Landscape in China: A Case of Kuancheng County, Hebei Province
}

\author{
Lulu He ${ }^{1,+}$, Qingwen Min ${ }^{2,3,+} \mathbb{D}$, Chuanchun Hong ${ }^{4,5}$ and Yongxun Zhang ${ }^{6, *}$ \\ 1 College of Humanities and Development, China Agricultural University, No.2 Yuanmingyuan West Road, \\ Haidian District, Beijing 100094, China; helulu@cau.edu.cn \\ 2 Institute of Geographic Sciences and Natural Resources Research, Chinese Academy of Sciences, 11A, \\ Datun Road, Chaoyang District, Beijing 100101, China; minqw@igsnrr.ac.cn \\ 3 University of Chinese Academy of Sciences, 19A Yuquan Road, Shijingshan District, Beijing 100049, China \\ 4 School of Management, Northeastern University at Qinhuangdao, Qinhuangdao 066004, China; \\ hongchuanchun@qhd.neu.edu.cn \\ 5 School of Business Administration, Northeastern University, Shenyang 110004, China \\ 6 Institute of Agricultural Economics and Development, Chinese Academy of Agricultural Sciences, \\ Zhongguancun South Street, Haidian District, Beijing 100081, China \\ * Correspondence: zhangyongxun@caas.cn; Tel.: +86-01082106193 \\ + These authors have an equal contribution to this article.
}

Citation: He, L.; Min, Q.; Hong, C.; Zhang, Y. Features and

Socio-Economic Sustainability of Traditional Chestnut Forestry Landscape in China: A Case of Kuancheng County, Hebei Province. Land 2021, 10, 952. https://doi.org/ 10.3390/land10090952

Academic Editor: María Fe Schmitz

Received: 25 July 2021

Accepted: 7 September 2021

Published: 8 September 2021

Publisher's Note: MDPI stays neutral with regard to jurisdictional claims in published maps and institutional affiliations.

Copyright: () 2021 by the authors. Licensee MDPI, Basel, Switzerland. This article is an open access article distributed under the terms and conditions of the Creative Commons Attribution (CC BY) license (https:// creativecommons.org/licenses/by/ $4.0 /)$
Abstract: Since Important Agricultural Heritage Systems (IAHS) were launched by the FAO to protect the sustainable traditional agricultural systems around the world, their conservation has become a new difficult issue under the context of urbanization. Farmers in IAHS sites giving up small-scale traditional farming due to their low economic benefit and high labor intensity are considered as the main cause hindering effective conservation of these heritages. This study takes the Kuancheng traditional chestnut cultivation system (KTCCS) in northern China as a case to assess its economic and socio-cultural sustainability. Based on questionnaires and interviews, this study found that: the traditional ecological farming methods were still used by local farming households to plant chestnut trees; and most farmers support IAHS conservation. KTCCS performs economic and socio-cultural sustainability. For a household, the labor productivity of chestnut cultivation was 1.33 times that of their non-farm jobs because of the low labor input of chestnut cultivation. Farmers widely consider they live in a harmonious social environment but are lower than other households in economic status. Most farmers still lack an understanding of indigenous traditional knowledge and cultures. In the future, secondary and tertiary industries should be developed to provide farmers with employment opportunities in their hometowns for protecting KTCCS.

Keywords: sustainability; labor productivity; nationally important agricultural heritage system (NIAHS); small farmer; agricultural landscape

\section{Introduction}

With the rapid development of agricultural technologies and the market-oriented economy, traditional agricultural systems are disappearing around the world $[1,2]$. There is a tendency that traditional agriculture with a small scale, low production efficiency and high labor demand is being replaced by industrial agriculture with a large scale, high production efficiency and low labor demand. However, modern industrial agriculture has shown negative environmental effects, such as soil compaction and acidification, owing to the overuse of chemical inputs [3] and lack of cultural, landscape-aesthetic, ecological value due to low biodiversity, high industrialization and short history. The merits of traditional agriculture have been receiving attention [4-6]. Especially, the Food and Agriculture Organization of the United Nations (FAO) initiated the Global Important Agricultural Heritage 
System (GIAHS) project in 2002 for protecting the outstanding traditional agricultural systems with a long history in the world $[7,8]$. Traditional agriculture has attracted the interest of researchers and governments $[9,10]$. For example, the governments of China, South Korea, and Japan in East Asia have launched the National Important Agricultural Heritage System (NIAHS) for extending the conservation scope of outstanding traditional agriculture systems since 2012 according to the GIAHS concept and selection criteria.

The GIAHS/NIAHS (hereafter called IAHS) is a sustainable land-use system and landscapes created by the indigenous people in IAHS sites are based on local climate, landform, and water resources. It was the remarkable land-use systems and landscapes which are rich in globally significant biological diversity that evolved from the co-adaptation of a community with its environment and its needs and aspirations for sustainable development according to the definition proposed by FAO. They have been testified by the history of hundreds or thousands of years as the agricultural production system with ecological sustainability [11-13]. They are a complex system covering social, economic, and cultural elements, for instance, traditional agricultural knowledge and technologies, local customs and etiquettes, and festivals [14,15]. From the perspective of resources, the IAHS has multiple functions, for example, economic, ecological, social, cultural, educational, landscape aesthetic, scientific research values and popularizing function $[14,16]$. The conservation for them has become a crucial task for the governments at different levels.

To maintain the traditional agricultural system such as IAHS is quite difficult due to the low benefit, high labor intensity and low production efficiency $[1,2,17,18]$. Generally, these traditional agricultural patterns belong to small-scale agriculture operated by small farmers and are considered by people as a backward agricultural model with low economic return $[19,20]$. IAHS conservation is thus a new challenge for the countries with IAHS in the world, especially for those countries with rapid socio-economic development under the context of the market-oriented economy. For example, terrace collapse and disrepair of ditch systems happened in Ifugao Terraces, the Philippines, because of local farmers abandoning rice farming for tourism [21,22]. Fortunately, IAHS in many places in China are still operated well by local small farmers now. For instance, farmland abandonment and disappearance of traditional farming models did not happen in Hani Terraces, Longji Terraces, and rice-fish coculture in Qingtian County [11,15]. Traditional forestry systems as a type of IAHS also still widely exist in China, which play an important role in making a living for people in the heritage sites due to their wide distribution [23]. Generally, there are lots of old trees in traditional forestry systems. They cannot be restored once destroyed. Therefore, exploring the socio-economic sustainable mystery of IAHS on forestry is significant to make effective agricultural heritage conservation policies better protect them.

Socio-economic sustainability of IAHS depends on households' decision-making in selecting their livelihood strategies. Households' behavioral decision-making is influenced by diverse factors. Studies show that small farmers in Africa making a decision, for example, the choice of climate-smart soil practices, adaption of new crop varieties or sustainable land management, was affected by their individual characteristics (e.g., age, education level, gender, farming experience, needs, aspirations or preferences), family operation conditions (e.g., farm size, plot size, field-to-house distance, family income) and external environment (e.g., policies, climate change, financing, neighbors' choice) [24-26]. In Asia, similar studies, for example, farmers' decision-making on abandoning agricultural land or adopting new agricultural inputs or technologies, present that their behaviors were driven by multiple factors, such as legal-managerial factor and individual ability [27,28]. In Australia, the studies on the adoption of conservation agriculture concluded whether conservation agriculture has a high benefit and farmers grasp relevant knowledge, and technologies are an influential factor $[29,30]$. In the Americas, studies on farmers' behavior present similar conclusions. Farmers' behaviors treating agro-climate services in Clarendon, Jamaica were affected by individual characteristics and family conditions [31]. Farmers' willingness to cooperate to control pests in Missouri, USA were determined by their expectation to benefit, 
neighbors' behaviors, the relationship with relevant stakeholders, and understanding of the environmental effect of cooperation [32]. In Europe, the factors influencing various farmers' decision-making have also been researched widely. For instance, whether farmers choose desalinated seawater for irrigation in south-east Spain was influenced by water quality, water price, crop diversity and previous experiences [33]. Strategic farm expansion decisions made by farmers was affected by both financial (e.g., non-farm income, profit) and non-financial factors (e.g., emotive reasons, social influence) [34]. Overall, drivers of a household's decision-making in different regions present similar features, including farmers' individual features, family operation condition, expected benefits and external social environment. However, for different events, the main factors influencing decisionmaking are different. At present, studies on small farmers' decision-making of farming and doing it according to traditional methods in IAHS sites are insufficient. Enhancing the study of the theme will contribute to the theoretical development of IAHS conservation.

Chestnut trees as a kind of fruit trees are widely distributed around China. In 2017, Chinese chestnut yield and export accounted for $83.3 \%$ and $26.4 \%$ of the total amount of the world. The Kuancheng Manchu Autonomous County of Hebei province (hereafter known as Kuancheng) is one of the most important areas that distribute Chinese old chestnut trees. There were more than 100,000 chestnut trees at over 100 years of age (Figure 1), and the oldest tree was 717 years in 2019 [35]. The Kuancheng Traditional Chestnut Cultivation System (KTCCS) was designated as the China NIAHS in 2014. Hence, protecting KTCCS has become an important task for people in Kuancheng. KTCCS as an agricultural heritage needs lots of farmers to continue to farm the old chestnut trees by traditional farming methods [9]. The willingness of chestnut farming households according to traditional farming methods is a key problem. In this study, taking chestnut farming households in Kuancheng as a study object, we examine the local chestnut farming households' income structure and cultivation willingness to reveal the current socio-economic sustainability of KTCCS, and at last propose policy suggestions for KTCCS conservation. We hope to provide a new perspective of conservation for forestry heritage sites and enrich the cases for building an effective mechanism of IAHS conservation.

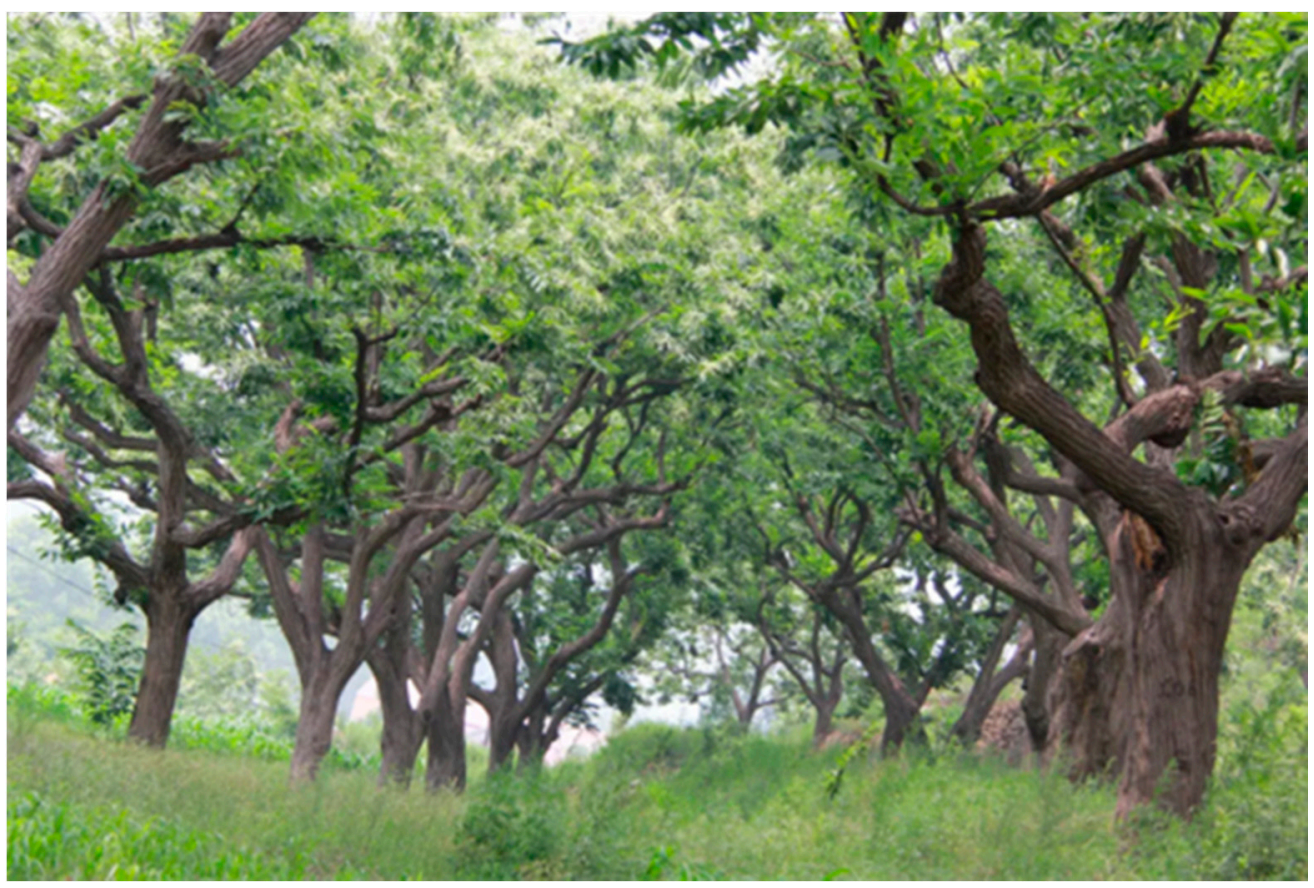

Figure 1. The old chestnut trees at over 100 years of age. 


\section{Materials and Methods}

\subsection{Study Area}

Kuancheng Manchu Autonomous County $\left(118^{\circ} 10^{\prime}-119^{\circ} 10^{\prime}\right.$ E, $\left.40^{\circ} 17^{\prime}-40^{\circ} 45^{\prime} \mathrm{N}\right)$, is located in the southeast of the Chengde Prefecture, Hebei Province, situated on the east section of Yanshan mountain (Figure 2). Its total area is $1936 \mathrm{~km}^{2}$. The elevation of most areas in the county is between 300 and $500 \mathrm{~m}$. There is a semi-arid and semi-humid continental monsoon climate zone, which is characterized by four distinct seasons, the hot and rainy season in summer and the cold and dry season in winter. The annual average temperature is $8.6^{\circ} \mathrm{C}$, and the annual rainfall is approximately $748 \mathrm{~mm}$. Soils are loose in texture and rich in trace elements such as iron, mainly composed of brown soil and cinnamon soil [36]. These natural conditions provide a quite suitable growing environment for chestnut trees, and also make the most contribution to the high quality of Kuancheng chestnuts.

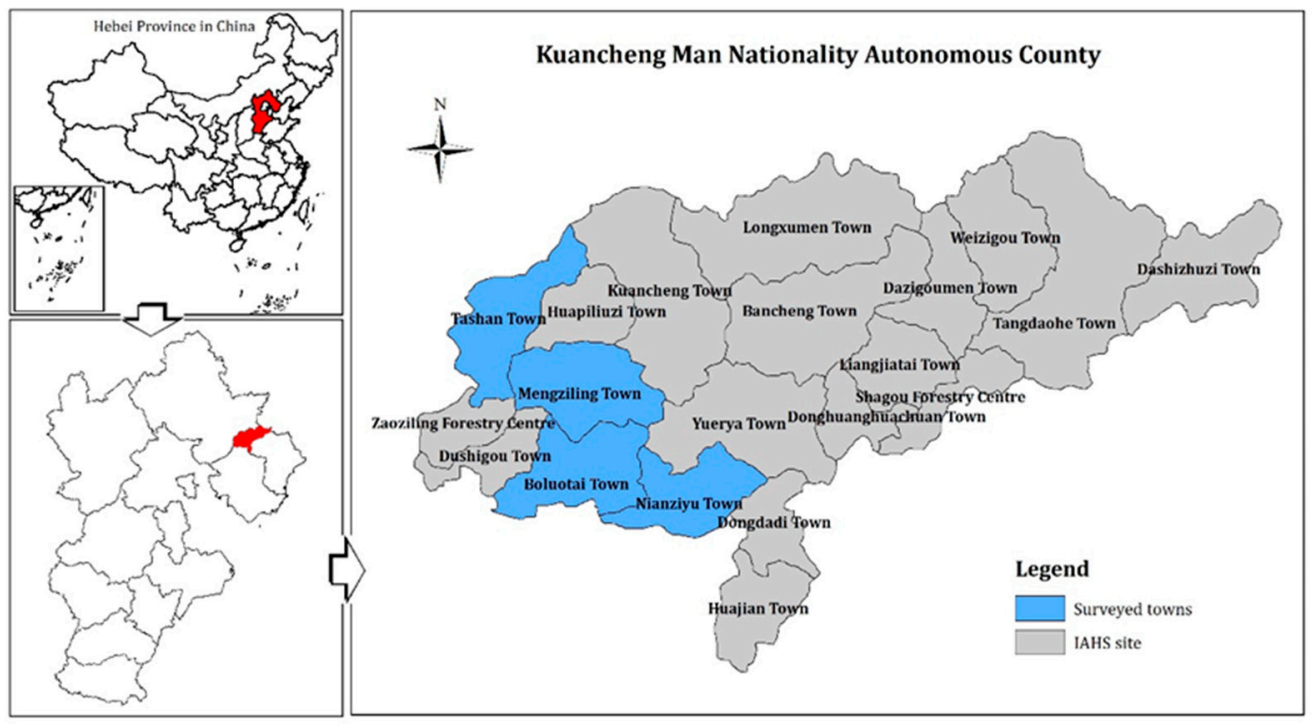

Figure 2. Position of Kuancheng and surveyed area.

On Yanshan mountain, the cultivation of chestnut trees has a history of more than 2240 years. The Master Lü's Spring and Autumn Annals (Pinyin: Lv Shi Chun Qiu; Chinese: 吕氏春秋), an ancient history book that collects diverse knowledge and ideologies of China, records that "there are three kinds of precious fruits, one of them is chestnut on Yanshan Mountain". Chestnut trees are extremely drought-tolerant and resistant to barren soils, which are usually called tree crops for ensuring food security owing to their strong resilience to natural disasters [37]. In the agricultural society, the number of chestnut trees represented wealth that a family enjoyed. Most chestnut trees were usually planted on the hills and mountains. Farmers first built level furrows or fish-scale pits on the slopes and then grew the chestnut tree seedlings in those furrows or pits. The traditional cultivated models can take full advantage of rainwater and also reduce the losses of soil and water. In relatively flat places, chestnut trees are intercropped with corns, soybeans, millets, and vegetables (Figure 3), and chickens are bred under chestnut trees (Figure 4). These cultivated models can not only make the most of local land and sunlight, but also achieve nutrient cycling in the forestry system. 


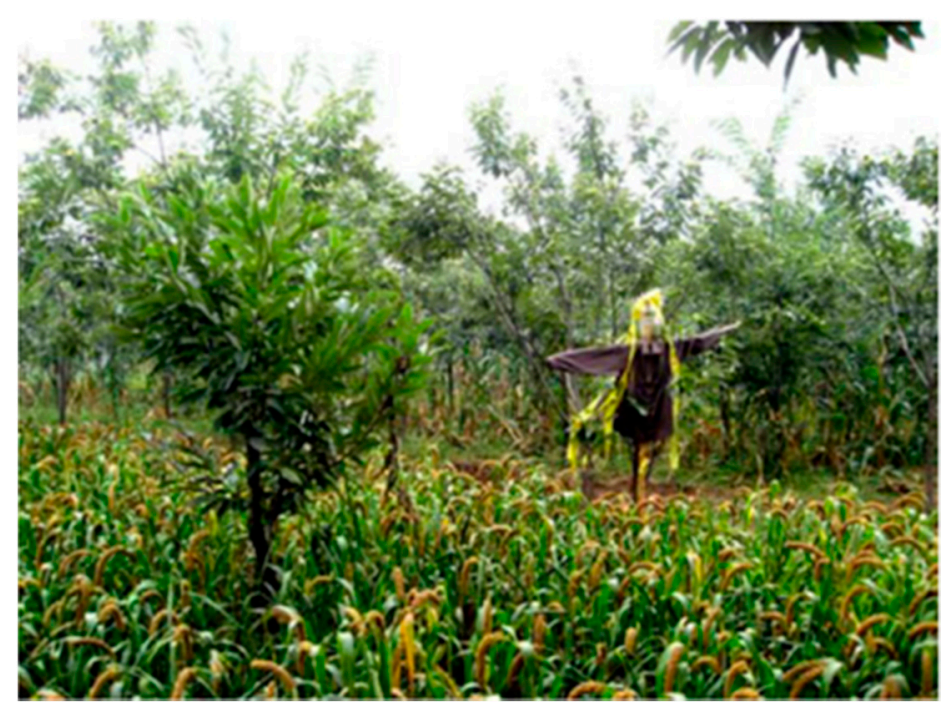

Figure 3. Intercropping of chestnuts and millets.

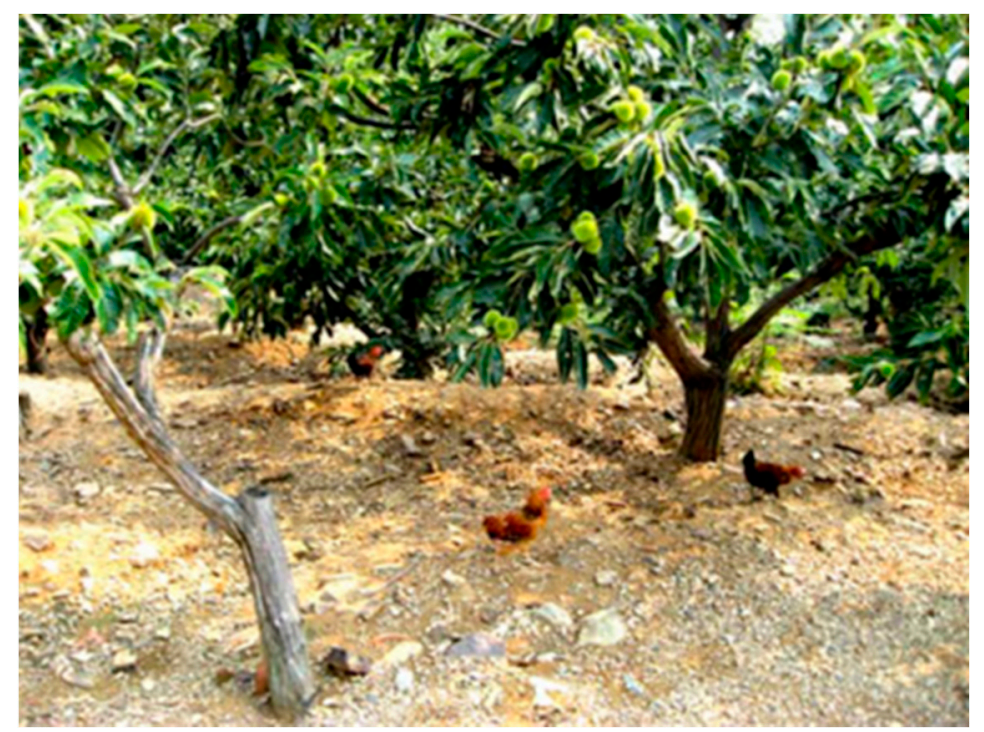

Figure 4. Breeding chickens under chestnuts.

In production management, traditional ecological farming methods are widely used by farmers to enhance chestnut yield [9,38], for example, implementing organic fertilizers such as manure and fallen leaves of chestnut trees to improve soil fertility, manually cutting and burning diseased branches or planting sunflowers to attract pests for controlling pests of chestnut trees. At present, KTTCS still keeps abundant biodiversity, for instance, more than 40 chestnut varieties widely planted in the system. The work of harvesting chestnuts is not complex, which just needs farmers to knock chestnuts off the trees and collect them when chestnuts ripen. Therefore, chestnut trees planted do not consume much labor. In Kuancheng, owing to most chestnut trees growing in harsh environmental conditions, they are hardly challenged by other economic trees such as apple and hawthorn with a higher profit rate according to our surveys. Therefore, lots of old chestnut trees over 100 years old still grow well and create economic value for local farmers [35].

In Kuancheng, diverse cultural forms related to chestnuts have been created by generation after generation of the people. Chestnuts have been endowed nice meanings by them, for example, lucky, profitable, victorious, aspiring ("chestnut" has a similar pronunciation to these words in Chinese). Chestnuts are the necessary food during festivals such as Dragon Boat Day, Middle Autumn Day, Spring Festival Day, and local customs such as weddings and important birthdays. Chestnuts have rich nutrients and are good for 
people's body health, which contain $5.7 \%$ protein, multiple vitamins, and microelements. Nowadays, fried chestnuts with sugar have become a very popular food in China, which can be bought in markets in most cities. However, with increasing migrant workers in KTCCS sites, urban lifestyles that they brought back are impacting local traditional cultures, for instance, the disappearance of traditional etiquettes and customs and loss of traditional farming knowledge.

Kuancheng is a typical forestry county. The total population was 261,941 by the end of 2018, of which the agricultural population was $62.6 \%$. The per capita disposable income of rural residents is 12,806 yuan ( 1 yuan $\approx 0.1511$ dollars in 2018). A small household is the unit of agricultural production. Kuancheng encompasses 18 towns. In 2018, the arable land area of the county was 14,600 ha. The fruit orchard area was 66,137, of which, the chestnut tree area was about 38,569 ha, constituting $58.3 \%$ of the fruit orchard area. Chestnut yield is about 38,000 tons, and the annual production value is 774 million yuan. The economic benefits of the chestnut industry accounted for more than $60.0 \%$ of the country's agricultural value. In China, land ownership belongs to the country, and farmers just have the contract and management right to land. Farmers contract farmland from the government by paying a certain agricultural tax per year. For encouraging farmers to farm, the Chinese central government announced the abolishment of the agricultural tax in 2006. Since then, farmers no longer had to pay agricultural tax to the government. According to various studies, in core production areas of Kuancheng, the chestnut income accounts for more than $80.0 \%$ of households' agricultural income [35]. However, the low income from agriculture cannot meet the increasing living cost of a family; thus, agricultural surplus labor in a family has to take non-farm jobs to improve their family income [39].

\subsection{Methods and Data Source}

KTCCS is a complex coupled human-nature system [40]. Its sustainability is impacted by internal and external factors. The economic and social environment that farmers live in is an important factor for farmers' career selection [15,41,42]. In order to explore the socioeconomic sustainability of Kuancheng chestnut forestry, we conducted a study according to the logic in Figure 5. The study content includes the current situation of chestnut production, farmers' attitudes to chestnut planting, and influencing factors on farmers decision-making. In the current situation of chestnut production, questions refer to whether farmers have chestnut orchards and how many areas they have, whether they rent chestnut orchards out, and how they manage their chestnut orchards (using lots of chemical inputs and pesticides, using a little, or not using any). In farmers' attitudes, questions contain whether farmers were willing to persist in planting chestnut trees, whether they would cut chestnut trees away when chestnut trees cannot earn money and why they make the decision, and whether to support protecting the KTCCS such as old chestnut trees and traditional farming methods. In the influencing factors, the economic factors (local households' living situation, the economic benefit of planting chestnut trees, expected income from chestnut operation) and the sociocultural factors (economic status in social circle, neighborhood, gaining respect sense, understanding level of chestnut cultivation and cultures, emotion such as a sense of pride in his/her hometown) were considered and investigated. 


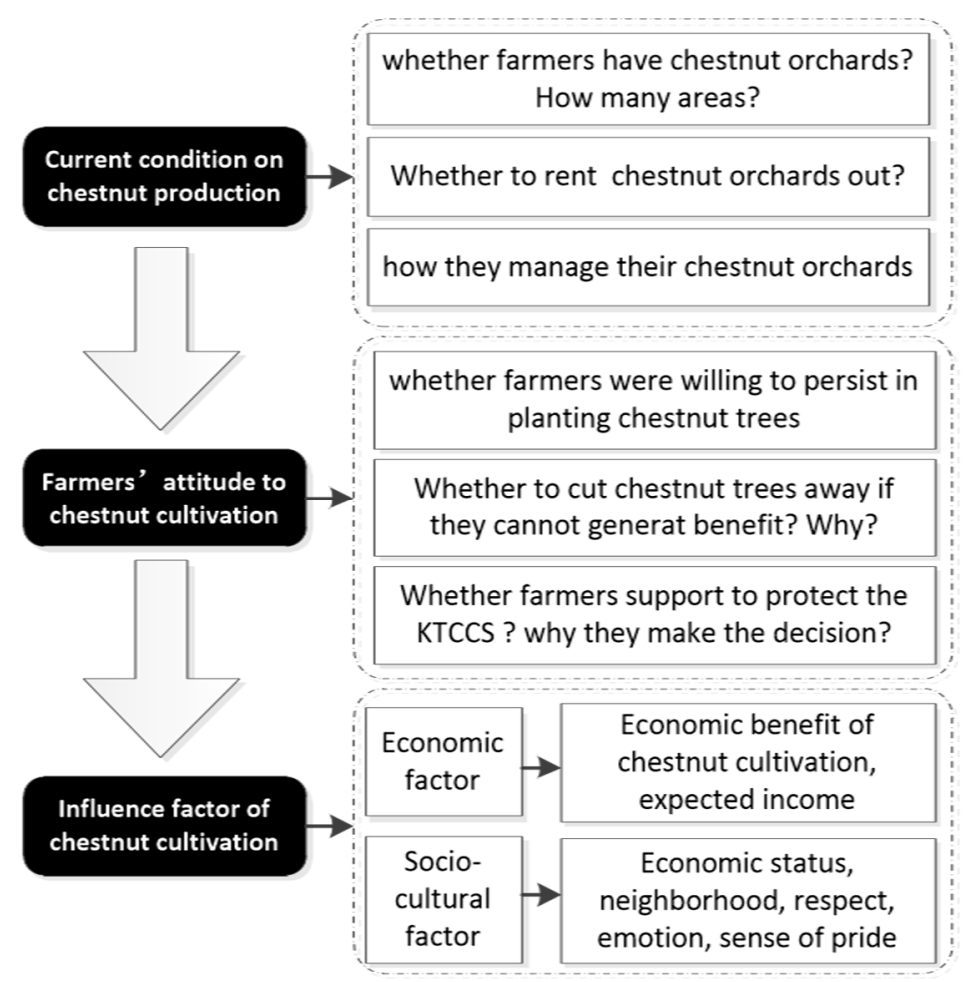

Figure 5. Research logic for Kuancheng chestnut forestry sustainability.

In Kuancheng, the towns that planted lots of chestnut trees were selected as the study area which includes Nianziyu Town, Tashan Town, Huajian Town and Poloutai Town (Figure 2). The four towns have $32.0 \%$ of the total chestnut orchards in Kuancheng. They were the main distribution area of the old chestnut trees and also the core area of KTCCS. In January 2019, villages were randomly selected to conduct a questionnaire survey in the study area. There were three villages chosen randomly in each township, and seven-nine respondents from different families in each village. The respondents were very knowledgeable about the technology of chestnut planting and the working conditions of their family members. One hundred and thirty questionnaires were distributed to respondents. Finally, 110 questionnaires were returned, among which 104 were valid. The respondents were ordinary chestnut farming farmers. According to the research logic in Figure 5, the questionnaire content includes the basic information of respondents (sex, education, family population, family employment), attitude of farmers to chestnut planting and KTCCS conservation and the sensing to living social environment. In addition, given that some parts of households cannot say the input-output of chestnut planting, we selected 22 of 110 respondents to conduct a semi-structured interview. The interview contents contain the chestnut production's material input, labor input, yield, chestnut price, family structure, labor amount, employment, salary and so on. Of those, 18 interviews are effective. All the information on the effective questionnaires was recorded and analyzed using Microsoft Excel 2010, and the figures were drawn using Microsoft Visio 2010.

\section{Results}

\subsection{Basic Characteristics of the Surveyed Households}

Of the respondents, $73.0 \%$ were male, which was higher than the number of females $(27.0 \%)$ (Table 1). Men generally have more skills in chestnut planting and knowledge because parts of the work such as pruning and mowing for harvesting chestnuts is very hard and mainly done by men. The respondents aged between 31 and 60 years old constitute the most of all (86.5\%), of which ages 31 to 40,41 to 50 and 51 to 60 accounted for $27.9 \%, 31.7 \%$ and $26.9 \%$, respectively. Most of the respondents have a middle education level. About $15.4 \%$ of the respondents said that they only received primary education or 
below; $46.1 \%$ received junior middle school education; $25.0 \%$ received senior middle school; and only $13.5 \%$ received junior college education or above. In addition, a rural household is mainly the stem family, with an average of $4.6( \pm 1.5)$ persons and $3.0( \pm 1.0)$ laborers per household, of which average agricultural laborers were $1.4( \pm 1.0)$ persons per household and average non-agricultural laborers were $1.6( \pm 0.8)$ persons per household. Overall, chestnut farmers presented a reasonable structure in age and relatively good education level than a large part of middle and west China $[15,43,44]$.

Table 1. Basic information of interviewed rural households.

\begin{tabular}{|c|c|c|c|c|c|c|c|}
\hline \multirow{2}{*}{$\begin{array}{c}\text { Sex } \\
\text { male }\end{array}$} & \multirow[b]{2}{*}{$73 \%$} & \multirow{2}{*}{$\frac{\text { Age }}{\text { below } 18}$} & \multicolumn{3}{|c|}{ Education } & \multicolumn{2}{|l|}{ Family Structure } \\
\hline & & & $1.0 \%$ & no school education & $1.0 \%$ & Total population & $4.6( \pm 1.5)$ \\
\hline female & $27 \%$ & $19-30$ & $2.9 \%$ & elementary & $14.4 \%$ & Laborers & $3.0( \pm 1.0)$ \\
\hline & & $31-40$ & $27.9 \%$ & junior middle school & $46.1 \%$ & Agricultural laborers & $1.4( \pm 1.0)$ \\
\hline & & $41-50$ & $31.7 \%$ & senior middle school & $25.0 \%$ & Non-agricultural laborers & $1.6( \pm 0.8)$ \\
\hline & & $51-60$ & $26.9 \%$ & college & $13.5 \%$ & & \\
\hline & & above 60 & $9.6 \%$ & & & & \\
\hline
\end{tabular}

\subsection{Attitude of Households to Planting Chestnut Trees in KTCCS Site}

Forest production systems need farmers to farm; thus, the attitude of rural households in KTCCS sites to planting chestnut trees directly influences the KTCCS' sustainability. To examine local rural households' willingness to plant chestnut trees is therefore essential to reveal the socio-economic sustainability of the KTCCS. In our survey, when the respondents were asked whether they were willing to persist in planting chestnut trees, they all answered "yes". When we went on asking them whether to cut the chestnut trees away and to plant other trees if they cannot earn money and why they would make the decision, $5.8 \%$ of them said they would cut those trees and plant other trees for improving income, $15.4 \%$ answered they cannot ensure whether they will cut their chestnut trees away and $78.8 \%$ said they would not cut their trees away because those trees contain important cultural values and the government prohibits cutting old chestnut trees according to the regulation of KTCCS conservation published by the Kuancheng government. When asked whether they support protecting KTCCS, almost all of them answered "yes", but one respondent who manages a large area of the modernized chestnut orchard ( $3.3 \mathrm{ha})$ did not agree. This is because KTCCS conservation requires farmers to manage chestnut trees according to traditional farming methods. Chemical agricultural inputs are not allowed to be used in the KTCCS site. This requirement can lead to labor input cost increases and chestnut yield decreases according to our interviews.

\subsection{Factors of Influencing Households to Planting Chestnut Trees}

\subsubsection{Economic Factor}

Our survey results show the whole situation that the chestnut industry contributes to households' income. The respondents were divided into four types according to the ratio of chestnuts to total family income: below $20 \%, 20-50 \%, 50-80 \%$ and above $80 \%$. The households whose income from chestnuts at below $20 \%$ and $20-50 \%$ of the total family income both accounted for $34.6 \%$ of the total sample, respectively. The households at $50-80 \%$ constituted $22.1 \%$, and the ones at above $80 \%$ were $8.7 \%$. The income from chestnuts is an important source of family income, but is not the main source for local households.

- Material inputs and outputs

Through interviewing the 18 households in detail, we grasped the general condition on inputs and outputs of planting chestnut trees. In China, land ownership belongs to the country; farmers just have the contract and management right of land. Farmers contract farmland from the government by paying a certain agricultural tax per year. Since 2006, farmers no longer needed to pay agricultural tax to the government due to this agricultural tax being abolished by the Chinese central government [45]. The direct 
material inputs of planting chestnut trees mainly include fertilizers, pesticides, irrigation and farm implements. As shown in Table 2, the fertilizer cost accounted for most of the total chestnut planting cost, which reached 932 Yuan/ha and accounted for $54.9 \%$ of the total input cost. The pesticides and farm implements were the second and the third, respectively. The least was irrigation, accounting for $8.8 \%$ of the total. The outputs of planting chestnut trees are mainly comprised of chestnuts and pruned branches. The branches have a lack of market demand, and farmers usually throw them away or use them as a living energy. The income from branches can thus be neglected. According to our survey, chestnuts yielded about $2771 \mathrm{~kg} / \mathrm{ha}$ and were purchased at the average price of about 13 yuan $/ \mathrm{kg}$ in 2018 . The direct material input cost of chestnut planting was 1699 yuan/ha. The net profit of chestnuts was 34,324 Yuan/ha. Each household has 0.75 ha of chestnut orchards, so the net profit of chestnut per household was 25,743 Yuan/household.

Table 2. Direct material input and output of chestnut planting.

\begin{tabular}{ccccc}
\hline Category & Material Inputs & Mean & Use Proportion (\%) & Total \\
\hline \multirow{2}{*}{ Direct material } & Fertilizer & 932 & 31.8 & \\
input (Yuan & Pesticide & 357 & 38.9 & 1699 \\
RMB/ha) & Irragation & 150 & 11.1 & \\
\hline Output (kg/ha) & Labor tool & 260 & 100 & 36,023 \\
\hline
\end{tabular}

- Agricultural activities and labor input for chestnut cultivation

In the KTCCS site, chestnut trees were planted mainly depending on manpower owing to being in a mountainous area; thus, the labor input was not much. As shown in Figure 6, the labor input is scattered and concentrates on four periods: the pruning period is from mid-January to mid-February; the main fertilizing period is in March; and the field management is from June to August, such as weeding, fertilizing, and spraying pesticides. In September, chestnut farmers work on picking up the chestnuts that naturally fall. In October and November, autumn fertilizer, commonly called by the people in the KTCCS site as "Yuezi fertilizer" ("Yuezi" in Chinese means the rehabilitation period after childbirth for one month; Yuezi fertilizer means the key fertilizer that supplements nutrients for the trees after chestnuts harvest), is conducted.

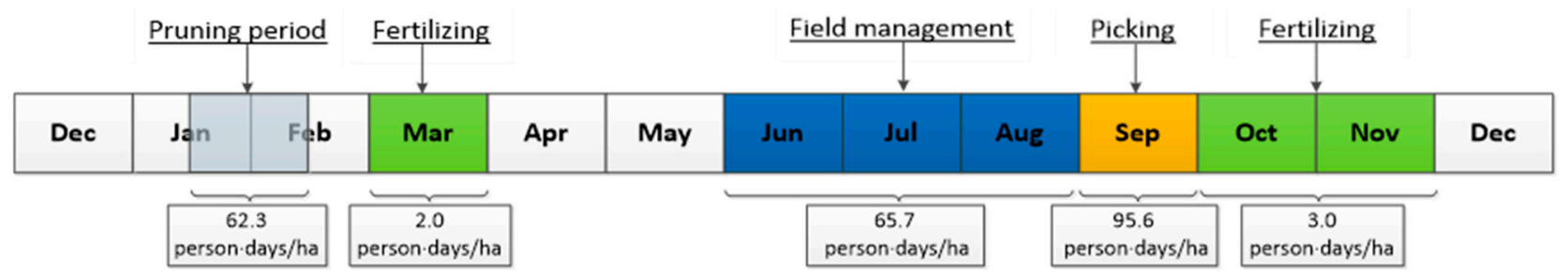

Figure 6. The seasonal distribution of labor input in planting chestnut trees.

The labor amount that these farming activities consume can be quantified by the unit person-days/ha. From the interviewed households, picking chestnuts took the most labor, 95.6 person-days/ha. Field management including weeding, medicating, and irrigation consumed 65.7 person.days/ha. Pruning and fertilizing just required 62.3 and 5.0 person.days/ha, respectively. Therefore, the total labor input was 228.6 person.days/ha. The amount of labor input for chestnut planting per household was 171.5 person-days, depending on 0.75 ha chestnut orchard per household.

- Labor productivity of non-farm jobs

There is a tendency that rural labor flows to urban areas with the development of urbanization, although planting chestnut plays an important role in the livelihood of local farmers. According to our survey, 5.5\% of migrant workers did non-farm jobs in 
his/her town, $27.8 \%$ working out of his/her town but in his/her county, $22.2 \%$ working out of his/her prefecture but in his/her province, $44.5 \%$ working out of his/her province. Due to the low education and lack of professional skills, migrant workers were only engaged in the jobs with low skill, low income, and poor stability, for instance, construction workers, hourly workers and waiters. Their work time was decided by the type of work. Usually, it was relatively scattered. The average salary level and work time of migrant workers show a trend that the farther they were away from their home, the higher their salary was and the longer their work time was (Table 3). The migrant workers in his/her town had 1500 yuan of salary and 8.0 months of work time; then it was 2800 yuan and 8.4 months for those working out of his/her town but in his/her county, followed by 3400 yuan/month and 9.3 months for those working in their province; the migrant workers in other provinces had the highest salary and the longest work time, 4000 yuan/month and 9.8 months, respectively. According to the weighted mean calculation, the average salary of the migrant workers was 3396 yuan/month, and the work time was a mean of 9.2 months/year (276 days/year according to 30 days/month). As we surveyed, there was an average 1.6 migrant workers in a household. As a result, the average income from non-farm jobs was 49,989 yuan/household.

Table 3. The work place, salary, and work time of migrant workers.

\begin{tabular}{cccc}
\hline \multirow{2}{*}{ Place } & Proportion & Salary & Work Time \\
\cline { 2 - 4 } & $\%$ & Yuan & Month \\
\hline In the town & 5.5 & 1500 & 8.0 \\
Out of the town but in the county & 27.8 & 2800 & 8.4 \\
Out of the prefecture but in the province & 22.2 & 3400 & 9.3 \\
Out of the province & 44.5 & 4000 & 9.8 \\
\hline Weighted average & - & 3396 & 9.2 \\
\hline
\end{tabular}

- Labor productivity of chestnuts and non-farm jobs and farmers' expected income for planting chestnut

Like the statement above, chestnut tree planting consumed labor for 171.5 person-days/ household and earns 25,743 Yuan/household. The non-farm jobs consumed 441.6 person-days/ household and earned 49,989 Yuan/household. In comparison, the labor productivity of chestnut planting was 150.1 yuan/(person·days), and that of non-farm jobs' was 113.2 yuan/(person·days). The former was 1.33 times the latter. It means the benefit of chestnut planting was not lower than non-farm jobs from the perspective of labor input-return rate.

When we surveyed local farmers' expectations of the income from planting chestnut if KTCCS would be designated as GIAHS, $58.5 \%$ of respondents held an optimistic attitude, $3.1 \%$ were pessimistic, and the rest said they could not predict future change trends. Optimistic respondents widely considered that Kuancheng chestnut popularity would rise and local government would give preferential policies and subsidies to chestnut farming households, and eventually, chestnut prices would rise. The pessimistic respondents said that they could not change the traditional farming methods at will and would cut chestnut trees in favor of growing other fruit trees. As a whole, farmers in the KTCCS site held a positive attitude to the influence that the GIAHS brand will generate. It is conducive to the sustainable development of KTCCS in the economic factor.

\subsubsection{Socio-Cultural Factor}

Indigenous farmers are the operators and managers of Kuancheng traditional chestnut orchards and the maintainers of traditional cultures. Whether they are in a harmonious rural social relationship affects their career selection and residential choice. Socio-culture is an important factor driving or restraining rural population flow, which usually plays an important role in individual decision-making [15]. Therefore, we surveyed the social relationship situations of chestnut farmers through three indexes (including the income level 
in their social group (economic status), the relationship between them and their neighbors (neighbor relationship) and whether they get respect from other people (respected sense)) and the emotion and understanding of local farmers to KTCCS and its relevant knowledge through three indexes (including understanding level of traditional knowledge on chestnut cultivation (farming knowledge), understanding level of local traditional agricultural culture (knowledge of traditional culture) and the view to KTCCS becoming GIAHS).

In the social relationship, each index was set to five grades according to the Likert scale (Table 4). In the economic status, according to our survey results, $47.6 \%$ of respondents considered that their economic income was a middle level in their social group; $36.6 \%$ thought they were the lower-income group and $13.4 \%$ said they were the lowest income group; just $2.4 \%$ considered themselves to belong to the higher income group, and no one attributed him/herself to the highest income group. Overall, about half the respondents did not feel economic pressure from their social group. All the respondents received 2.4 points of the mean value according to the calculation method of the Likert scale. In the neighbor relationship, $42.7 \%$ of respondents said they had a very friendly relationship with their neighbors; the rest (57.3\%) thought they were friendly with their neighbors, and no one considered that they had a simple, not good or terrible relationship with neighbors. All of them considered their neighborhood to be harmonious and their Likert score was 4.4 points. In the respected sense, $9.8 \%$ and $40.2 \%$ respondents selected "strongly agree" and "agree", i.e., they thought they received enough or basic respect from other people; $40.5 \%$ respondents selected "neutral"; $3.6 \%$ and $4.9 \%$ ones selected "disagree" and "strongly disagree", i.e., they considered they did not get respect from other people in their village. Respondents attained 3.5 points of Likert score in the respected sense.

Table 4. Social relationship situation of chestnut farming farmers.

\begin{tabular}{|c|c|c|c|c|c|c|}
\hline \multirow[t]{2}{*}{ Social Relationship } & \multicolumn{2}{|c|}{$\begin{array}{c}\text { Economic Status } \\
(\%)\end{array}$} & \multicolumn{2}{|c|}{$\begin{array}{c}\text { Neighbor Relationship } \\
(\%)\end{array}$} & \multicolumn{2}{|c|}{$\begin{array}{c}\text { Respected Sense } \\
(\%)\end{array}$} \\
\hline & highest & 0.0 & very friendly & 42.7 & Strongly agree & 9.8 \\
\hline \multirow{4}{*}{ Grade } & higher & 2.4 & friendly & 57.3 & Agree & 40.2 \\
\hline & middle & 47.6 & simple & 0 & Neutral & 40.5 \\
\hline & lower & 36.6 & not good & 0 & Disgree & 3.6 \\
\hline & lowest & 13.4 & terrible & 0 & Strongly disagree & 4.9 \\
\hline
\end{tabular}

Depending on the theory of the Likert scale, a score equaling or exceeding 3.5, between 2.5 and 3.5 , and below 2.5 present the respondents to have a high level, a middle level, and a low level, respectively [46]. Local farmers were satisfied with their neighborhood and sense of respect, but not satisfied with their income status. We can see that most farmers were in a relatively harmonious social environment.

In emotion and understanding, each index was set to three grades (Table 5). In the farming knowledge, according to our survey results, $31.7 \%$ of respondents said they knew much traditional knowledge about chestnut cultivation; more than half of respondents (54.9\%) thought they knew some, and the rest (13.4\%) said they were just acquainted with a little. In the knowledge on traditional culture, the result shows a similar proportion. The respondents who know much local traditional culture accounted for $37.8 \%$; the ones who know some were $56.1 \%$, and the ones who know little constituted $6.1 \%$. In the view to KTCCS becoming GIAHS, when the respondents were asked whether they would be proud if the KTCCS was designated as GIAHS, 58.8\% of them said that they would have pride in obtaining the certification. A total of $40.0 \%$ of them said that they did not know because they were not aware of GIAHS. Just a few respondents $(1.2 \%)$ held a negative attitude (no pride). With increasing knowledge on GIAHS, they will discover the economic, cultural and social value of KTCCS and improve their place identification, and also have more love for KTCCS [42]. 
Table 5. The emotion and understanding of local farmers to chestnut cultivation.

\begin{tabular}{cccc}
\hline Category & Much/Pride & Some/Unclear & Little/No Pride \\
\hline Farming knowledge & 31.7 & 54.9 & 13.4 \\
Knowledge on agricultural culture & 37.8 & 56.1 & 6.1 \\
View to KTCCS becoming GIAHS & 58.8 & 40.0 & 1.2 \\
\hline
\end{tabular}

\section{Discussion}

IAHS is a living heritage with a food production function, different from natural heritage, cultural heritage, and intangible cultural heritage, which refers to not only crop varieties, agricultural landscapes and ecosystems, but also traditional knowledge and techniques and local social cultures [47]. The precious agricultural production and management knowledge it contains can help modern agriculture to achieve sustainable development. The FAO calls it "A legacy for the future" [7]. IAHS conservation is a significant topic, but also a new and difficult issue because of covering various elements and its complex interaction mechanism. Studies have shown that economic and socio-cultural factors are playing a balancing role in rural social development and changes, but the effect of the economic factor is enhancing with urbanization $[2,15,48]$.

This study took KTCCS as a case to analyze its sustainability from the perspective of the economy and socio-culture. Positive and negative factors influenced KTCCS conservation together (Figure 7). Our study shows young and middle-aged people constitute a large part of farming labors in KTCCS. However, in most GIAHS sites in the world, population aging has become an important threat to sustainability of GIAHS due to young labor outmigration. They have to introduce young talents from other areas to maintain the GIAHS through diverse incentive policies [42,49,50]. For KTCCS, a better age structure of laborers keeps the strong resilience of KTCCS.

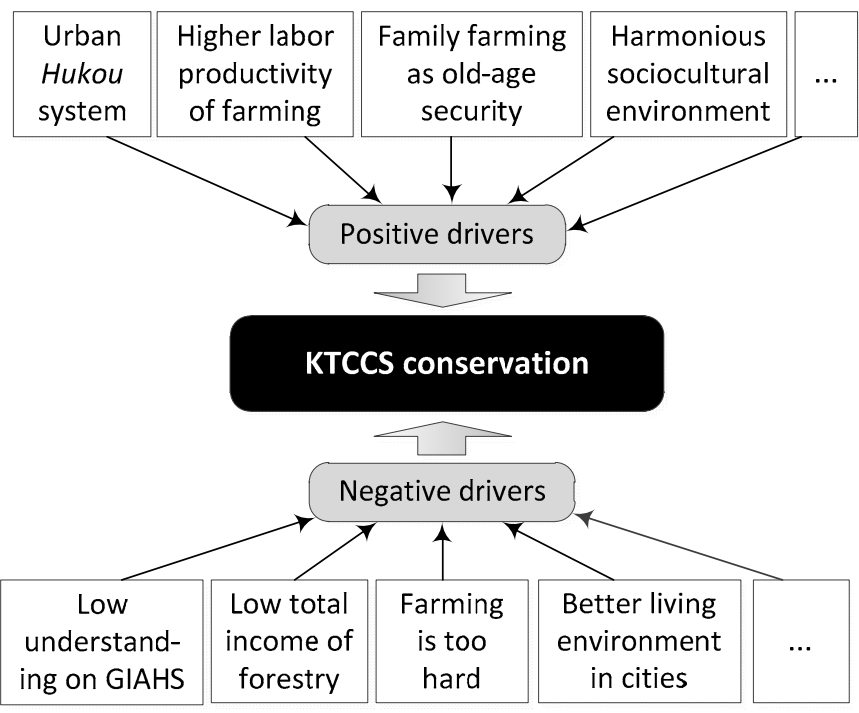

Figure 7. Positive and negative drivers of KTCCS conservation.

The economic factor was still a pulling power for local farmers in the KTCCS site according to our study results. Chestnut farming households did not have a high income from chestnut cultivation (it accounts for $34.0 \%$ of the total family income), but they also input less labor to farm (it just accounts for $27.7 \%$ of the total family labor amount). Obviously, chestnut cultivation was worthy of inputting labor for local farmers in economic benefit. This result is consistent with other studies, for example, agricultural productivity benefit as a main factor in change of farming practices and the adoption of new agricultural technologies [30,32]. On the contrary, farmers tend to abandon agriculture to start full-time non-farm jobs if they find the labor input return rate from non-farm jobs to be far higher 
than from agriculture [51]. This may be an important reason to explain why lots of full-time farmers did not abandon their farmland but became the part-time farmers [23].

Socio-culture is also an important factor to influence farmers' employment selection. Studies on the sustainability of Hani terraces suggest that traditional cultures limit local farmers' selection of non-farm employment places and types. However, they generate a positive function to Hani terrace conservation due to few people's outmigration [15]. Kuancheng is a minority region but does not have obvious ethnic-cultural characteristics, similar to Han nationality in culture. Hence, we just studied the social environment that local farmers live in and individual features that influence farmers' decision-making [52]. Our study shows local farmers are not only in a harmonious social relationship but also in a pressure status from the income gap with other households. In the individual understanding of local cultures, local farmers have a better level, and this can promote their conservation activities to KTCCS. However, most respondents do not know what GIAHS is and cannot take pride in KTCCS becoming GIAHS. This reflects that the improvement of farmers' understanding of IAHS through wide publicity is an urgent work for local government.

Besides the agricultural benefit and socio-culture influence, the administration system also has a comprehensive influence on KTCCS conservation through some indirect approaches. For example, the Chinese urban household registration (Chinese: hukou) system hinders the change from rural residents to urban residents. In some senses, it is a positive factor to protect KTCCS. The people who have no urban hukou cannot enjoy public services [53]. For instance, their children cannot enjoy the free education right from nursery school to junior middle school provided by the cities. For those temporary workers without the urban hukou, they cannot enjoy the social insurance and the housing fund by companies in cities. For farmers, employment after graduation from colleges or buying houses in cities is the main path to obtain urban hukou. It is very difficult to become a citizen living in cities for the migrant workers in IAHS sites. The obstacle of the hukou system enhances the living cost of migrant workers in cities. Lots of farmers have to do non-farm jobs in cities during the slack farming season as a livelihood strategy change responding to living cost increases. In a sense, the urban hukou system ensures enough labor in IAHS sites and benefits for IAHS conservation.

In China, family farming is still an important old age security for farmers under the current hukou system. Chestnut cultivation in Kuancheng is operated and managed by small farmers. Like most small farmers in China, a large part of small farmers are not fulltime farmers, who are both engaged in agricultural production and non-farm work $[3,54]$. The low labor input of agriculture enables them to adapt to the socio-economic transition by changing their livelihood strategies. It also demonstrates the sustainability of small-scale family farming today. The labor force of KTCCS is aging, though it is not serious like in some other rural areas [15,42]. It is common that young people go to cities for non-farm jobs, but their non-farm employment opportunities will decrease as they grow older [55]. When they reach a certain age, they have to return to their hometown to farm and enjoy their old age [44]. These phenomena prove that small-scale family farming still plays an irreplaceable role in China's social development in the future to come [56,57]. Essentially, KTCCS as the China NIAHS is still maintained well by local small farmers depending on its higher labor productivity.

Agriculture is a seasonal industry which hardly continually improves profit per unit area through input increases. Hence, the income from agriculture is limited for farmers (Figure 6). In addition, according to our interviews, respondents widely believed that farming is too hard and around $70.0 \%$ of them hope to live in cities because the living environment in cities is better. It is an inexorable trend that the rural population migrates to cities due to the economic benefit driver and the requirement for living environment improvement [1,2]. The trend has resulted in tremendous changes in traditional agricultural systems such as hollow villages and farmland abandonment $[17,18,58]$. Therefore, IAHS conservation will face severe challenges in the future due to the losses of farmers. 
To improve the income of farmers in IAHS sites, many studies propose countermeasures to encourage farmers to farm, for example, payment for ecosystem services [38] and price compensation for products from the traditional agricultural system [41]. This study showed developing the secondary and tertiary industry to absorb surplus rural labor is a sustainable way. The low labor input of small-scale agriculture also allows local small farmers to engage in non-farm jobs in their hometowns. For example, they can develop rural tourism by integrating local agricultural product processing, manufacturing, agricultural landscape, ecological environment and traditional culture [59,60]. Local industrial development not only can contribute to the stability of local social structure and reduce social problems such as divorce, crime and old-age care, but also ensure the integrity of peasant families, the healthy growth of children and the protection of local culture $[15,61,62]$. It can promote KTCCS conservation through keeping farmers planting chestnut trees and learning indigenous traditional farming knowledge and culture in their hometown.

In this study, we just used representative indicators reflecting the key agricultural features of KTCCS to explain the socio-economic sustainability of KTCCS from the perspective of sociology. Through the randomly questionnaires, we obtained an overall figure of the population structure, rural social relationship and local farmers' cognitions and attitudes to IAHS in KTCC. We are also aware of the situation of forestry production operated by small farmers using interviews. This information gives us an insight into the socioeconomic sustainability of KTCCS. However, there are some shortcomings of this study due to the limitations of the samples. For instance, we cannot build an accurate cause-effect relationship between the sustainability of KTCCS and their drivers. Our results did not reach strict statistical significance. Therefore, the sustainability mechanism of KTCCS still needs deep research based on a more comprehensive consideration of affecting population outmigration and KTCCS changes, covering macro-economic environment, hukou system reform, rural land transfer and the progress of agricultural technologies. Quantified studies from micro-perspectives are necessary based on large samples for revealing the influence of a single factor on socio-economic sustainability.

\section{Conclusions and Recommendations}

\subsection{Conclusions}

This study examined the current situation of chestnut production, farmers' attitude to chestnut cultivation, and the main influence factors. We conclude that approximately $60 \%$ of local farmers are young labor forces, and over $70 \%$ of them accepted middle school education. They show a relative reasonable labor structure in age and good labor quality for farming. Most farmers persist in planting chestnut industries themselves, and hardly rent out or abandon their chestnut trees. About half of them plant chestnut trees using traditional farming methods. Most farmers plan to persist in planting chestnut trees even if the industry cannot earn a high income. They hold a positive attitude to planting chestnut trees. Therefore, it greatly benefits KTCCS conservation.

This study also contributes a new perspective to understand economic sustainability of small farmers in China. In the KTCCS site, chestnut cultivation has higher labor productivity compared with the non-farm jobs for a chestnut farming household because small-scale forestry just needs a few laborers for production due to the extensive management. It means that the labor input return rate of chestnut cultivation was not low (it is 1.33 times of non-farm jobs) and proves economic sustainability of KTCCS. This result also gives a persuasive answer to why Chinese small-scale agriculture still exists widely. It also demonstrates Chinese small farmers enjoy economic rationality.

Our study denotes local farmers have a relatively harmonious and acquainted social living environment. It will not happen that lots of chestnut farmers migrate out of their village for the reason of bad relationships with their neighbors and other villagers. Kuancheng traditional chestnut planting industries have a better social base. Most farmers know local traditional knowledge and culture to some extent, and also have deep emotion 
about their homeland. Therefore, the socio-cultural factors generate positive impacts on IAHS conservation.

On the whole, current economic and social factors drive the local small farmers to maintain the KTCCS now and benefit the conservation and sustainable development of KTCCS. However, local farmers' high economic status expectation and low understanding level of IAHS are generating negative influences to keep the sustainability of KTCCS.

\subsection{Recommendations}

The IAHS conservation will not be achieved without the participation of local farmers. The main driver of farmers protecting IAHS lies in whether they obtain a higher economic income from the job to meet their living needs and whether they gain a positive emotion. Therefore, it is necessary to make full use of farmers' leisure time to improve their income in IAHS sites and to strengthen their emotion to their hometowns and KTCCS [15,63]. To make local farmers stay in their hometowns, the local government needs to take incentive measures as follows:

First is to improve farmers' understanding of IAHS values and conservation implication and their skills to develop multi-functional agriculture. For example, technical extension experts teach local farmers skills of planting and managing chestnut trees through TV programs. Communities, cooperatives, or other non-government organizations cooperate with some agricultural universities or institutes and invite their scientists to teach chestnut farmers knowledge on IAHS conservation and operating diverse industries based on KTCCS.

The second is to promote integration of industries to resolve the employment of surplus labor. For instance, chestnut processing industries and rural tourism are developed based on traditional chestnut landscapes, relevant cultural landscapes, and learning and experiences of planting chestnut by making tax-free or reward policies. These secondary and tertiary industries can provide employment opportunities for farmers during farm slack seasons. Farmers are encouraged to develop compound cultivation patterns, for example, planting chestnut mushrooms and chickens under chestnut trees through ecological compensation policies for extending agricultural labor time and increasing yields.

The third is to build a multimedia marketing platform by the Kuancheng government to help farmer publicity and to brand Kuancheng chestnuts with IAHS. Branding of products can raise the price of chestnuts and then improve the economic benefit of local farmers. Finally, it is more important to improve local farmers' cultural pride and hometown attachment through publicity and training of IAHS knowledge and techniques so that they cherish and utilize the precious resources.

Author Contributions: Conceptualization, Y.Z. and Q.M.; methodology, Q.M. and Y.Z.; software, Y.Z.; formal analysis, C.H.; investigation, L.H., C.H. and Y.Z.; writing-original draft preparation, L.H.; writing — review and editing, Y.Z.; project administration and funding acquisition, Q.M. and Y.Z. All authors have read and agreed to the published version of the manuscript.

Funding: This research was financed by the projects of "'Beautiful China' Ecological Civilization Construction Science and Technology Project (XDA23100203)", "Agricultural Science and Technology Innovation Project of Chinese Academy of Agricultural Sciences (CAAS-ASTIP-IAED-2021-06; STIPIAED-2021-ZD-02)" and the project of "Study of Kuancheng Traditional Chestnut Cultivation System" granted by Kuancheng Man Autonomous County, Hebei Province.

Institutional Review Board Statement: Not applicable.

Informed Consent Statement: Not applicable.

Data Availability Statement: Not applicable.

Acknowledgments: The authors would like to thank officers in the Bureau of Agriculture and Rural Affair, Kuancheng Man Autonomous County and Y.B. in the Institute of Geographic Sciences and Natural Resources Research, Chinese Academy of Sciences, for their help in surveys, and also sincerely thank the editors and anonymous referees for working hard. 
Conflicts of Interest: The authors declare no conflict of interests.

\section{References}

1. Lieskovský, J.; Kankab, R.; Bezáka, P.; Štefunková, D.; Petrovič, F.; Dobrovodská, M. Driving forces behind vineyard abandonment in Slovakia following the move to a market-oriented economy. Land Use Policy 2013, 32, 356-365. [CrossRef]

2. Šspulerová, J.; Piscová, V.; Gerhátová, K.; BačA, A.; Kalivoda, H.; Kanka, R. Orchards as traces of traditional agricultural landscape in Slovakia. Agric. Ecosyst. Environ. 2015, 199, 67-76. [CrossRef]

3. Guo, J.H.; Liu, X.J.; Zhang, Y.; Shen, J.L.; Han, W.X.; Zhang, W.F.; Christie, P.; Goulding, K.W.; Vitousek, P.M.; Zhang, F.S. Significant Acidification in Major Chinese Croplands. Science 2010, 327, 1008-1010. [CrossRef] [PubMed]

4. Ellis, E.C.; Wang, S.M. Sustainable Traditional Agriculture in the Tai Lake Region of China. Agric. Ecosyst. Environ. 1997, 61, 177-193. [CrossRef]

5. Harrop, S.R. Traditional agricultural landscapes as protected areas in international law and policy. Agric. Ecosyst. Environ. 2007, 121, 296-307. [CrossRef]

6. Madejon, P.; Barba-Brioso, C.; Lepp, N.W.; Fernandez-Caliani, J.C. Traditional agricultural practices enable sustainable remediation of highly polluted soils in southern spain for cultivation of food crops. J. Environ. Manag. 2011, 92, 1828-1836. [CrossRef] [PubMed]

7. FAO. Globally Important Agricultural Heritage Systems. Available online: http://www.fao.org/giahs/become-a-giahs/en/ (accessed on 25 April 2020).

8. Koohafkan, P.; dela Cruz, M.J. Global important agricultural cultural heritage (GIAHS) protection and adaptive management. J. Resour. Ecol. 2011, 2, 22-28.

9. Min, Q.W.; Zhang, Y.X.; Jiao, W.J.; Sun, X.P. Responding to common questions on the conservation of agricultural heritage systems in China. J. Geogr. Sci. 2016, 26, 969-982. [CrossRef]

10. Zhang, Y.X.; He, L.L.; Min, Q.W. Research progress of agricultural heritage in China based on literature statistics. Resour. Sci. 2017, 39, 175-187, (In Chinese with English Abstract).

11. Xie, J.; Hu, L.; Tang, J.; Wu, X.; Li, N.; Yuan, Y.; Yang, H.; Zhang, J.; Luo, S.; Chen, X. Ecological mechanisms underlying the sustainability of the agricultural heritage rice-fish coculture system. Proc. Natl. Acad. Sci. USA 2011, 108, E1381-E1387. [CrossRef]

12. Zhang, Y.; Liu, M.; Min, Q.; Lun, F.; Zhang, C. Environmental adaptability and service function of Chinese jujube forest ecosystem in Jiaxian County Shaanxi Province. Arid Zone Res. 2014, 31, 416-423, (In Chinese with English Abstract).

13. Chowdhury, R.B.; Moore, G.A. Floating agriculture: A potential cleaner production technique for climate change adaptation and sustainable community development in Bangladesh. J. Clean. Prod. 2017, 150, 371-389. [CrossRef]

14. Zhang, Y.; Min, Q.; Jiao, W.; Liu, M. Values and conservation of Honghe Hani Rice Terraces System as a GIAHS Site. J. Resour. Ecol. 2016, 7, 197-204.

15. Zhang, Y.; Min, Q.; Zhang, C.; He, L.; Zhang, S.; Yang, L. Traditional culture as an important power for maintaining agricultural landscapes in cultural heritage sites: A case study of the Hani terraces. J. Cul. Herit. 2017, 25, 170-179. [CrossRef]

16. He, L.; Min, Q.; Zhang, D. Evaluation models for multifunctionality of agriculture and their applications: A case study on Qingtian country in Zhejiang Province, China. Resour. Sci. 2010, 32, 1057-1064, (In Chinese with English Abstract).

17. Ge, L.; Gao, M.; Hu, Z.; Han, X. Reasons of cultivated land abandonment in mountainous area based on farmers' perspective Chin. J. Agric. Resour. Regional Plan. 2012, 33, 42-46, (In Chinese with English Abstract).

18. Sluis, T.; Kizos, T.; Pedroli, B. Landscape change in Mediterranean farmlands: Impacts of land abandonment on cultivation terraces in Portofino (Italy) and Lesvos (Greece). J. Landsc. Ecol. 2014, 7, 23-44. [CrossRef]

19. Mao, Z.; Cheng, Y. Analysis of reasons and countermeasures for low comparative agricultural benefits: A case study of Zhejiang Province. Prod. Res. 2017, 10, 63-65, (In Chinese with English Abstract).

20. Fu, P.; Tang, D. The causes and countermeasures of low comparative agricultural benefits in China. South. China Agric. 2012, 6, 83-85. (In Chinese)

21. Calderon, M.; Dizon, J.; Sajise, A.; Andrada, R.; Bantayan, N.; Salvador, M. Towards the Development of a Sustainable Financing Mechanism for the Conservation of the Ifugao Rice Terraces in the Philippines; Eepsea Research Report; EEPSEA and IDRC, East Asia; 2009.

22. Bantayan, N.C.; Calderon, M.M.; Dizon, J.T.; Sajise, A.J.U.; Salvador, M.G. Estimating the extent and damage of the UNESCO world heritage sites of the Ifugao. J. Environ. Sci. Manag. 2012, 15, 1-5.

23. National Bureau of Statistics. Third National Agricultural Census Main Data Bulletin (NO.1). Available online: http://www.stats. gov.cn/tjsj/tjgb/nypcgb/qgnypcgb/201712/t20171214_1562740.html (accessed on 22 April 2020).

24. Mugumaarhahama, Y.; Mondo, J.M.; Cokola, M.C.; Ndjadi, S.S.; Mutwedu, V.B.; Kazamwali, L.M.; Cirezi, N.C.; Chuma, G.B.; Ndeko, A.B.; Ayagirwe, R.B.B. Socio-economic drivers of improved sweet potato varieties adoption among smallholder farmers in South-Kivu Province, DR Congo. Sci. Afr. 2021, 12, e00818.

25. Mogaka, B.O.; Bett, H.K.; Ng'Ang'A, S.K. Socioeconomic factors influencing the choice of climate-smart soil practices among farmers in Western Kenya. J. Agric. Food Res. 2021, 5, 100168. [CrossRef]

26. Emerton, L.; Snyder, K.A. Rethinking sustainable land management planning: Understanding the social and economic drivers of farmer decision-making in Africa. Land Use Policy 2018, 79, 684-694. [CrossRef] 
27. Movahedi, R.; Jawanmardi, S.; Azadi, H.; Goli, I.; Witlox, F. Why do farmers abandon agricultural lands? The case of Western Iran. Land Use Policy 2021, 108, 105588. [CrossRef]

28. Aua, B.; Ma, A.; Hka, C.; Az, D.; Nm, A.; Kma, E. Socio-economic analysis of farmers facing asymmetric information in inputs markets: Evidence from the rainfed zone of Pakistan. Technol. Soc. 2020, 63, 101405.

29. D'Emden, F.H.; Llewellyn, R.S.; Burton, M.P. Factors influencing adoption of conservation tillage in Australian cropping regions. Aust. J. Agric. Resour. Econ. 2008, 52, 169-182. [CrossRef]

30. Rochecouste, J.; Dargusch, P.; Cameron, D.; Smith, C. An analysis of the socio-economic factors influencing the adoption of conservation agriculture as a climate change mitigation activity in Australian dryland grain production. Agric. Syst. 2015, 135, 20-30. [CrossRef]

31. Buckland, S.F.; Campbell, D. An assessment of factors influencing awareness, access and use of agro-climate services among farmers in Clarendon, Jamaica. Geoforum 2021, 126, 171-191. [CrossRef]

32. Stallman, H.R.; James, H. Determinants affecting farmers' willingness to cooperate to control pests. Ecol. Econ. 2015, 117, 182-192. [CrossRef]

33. Aznar-Sánchez, J.A.; Belmonte-Urea, L.J.; Velasco-Muoz, J.F.; Valera, D.L. Farmers' profiles and behaviours toward desalinated seawater for irrigation: Insights from south-east Spain. J. Clean. Prod. 2021, 296, 126568. [CrossRef]

34. Hayden, M.T.; Mattimoe, R.; Jack, L. Sensemaking and the Influencing factors on Farmer Decision-making. J. Rural Stud. 2021, 84, 1-15. [CrossRef]

35. Zheng, J.H. Agricultural Heritage Brand Makes Ordinary Chestnuts become Golden Chestnuts. Farmers' Daily, 7 August 2018. Available online: http://szb.farmer.com.cn/nmrb/html/2018-08/07/nw.D110000nmrb_20180807_6-01.htm?div=-1 (accessed on 15 April 2020). (In Chinese).

36. Zhang, X.; Zhao, J.; Yao, Z.; Zhang, W.; Zhao, S. Chestnut fertilization technology in Kuancheng county. Mod. Rural. Sci. Technol. 2017, 11, 46. (In Chinese)

37. Craddock, J.H.; Perkins, M.T. Chestnut (Castanea spp. Miller) Breeding. In Advances in Plant Breeding Strategies: Nut and Beverage Crops; Al-Khayri, J., Jain, S., Johnson, D., Eds.; Springer: Cham, Germany, 2019; pp. 105-156.

38. Liu, M.; Xiong, Y.; Yuan, Z.; Min, Q.; Sun, Y.; Fuller, A.M. Standards of ecological compensation for traditional eco-agriculture: Taking rice-fish system in Hani terrace as an example. J. Mt. Sci. 2014, 11, 1049-1059. [CrossRef]

39. Xu, Z.Q.; Min, Q.W. Hebei Kuancheng Traditional Chestnut Cultivation System; China Agriculture Press: Beijing, China, 2019.

40. Liu, J.; Dietz, T.; Carpenter, S.R.; Alberti, M.; Folke, C.; Moran, E.; Pell, A.N.; Deadman, P.; Kratz, T.; Lubchenco, J.; et al. Complexity of coupled human and natural systems. Science 2007, 317, 1513-1516. [CrossRef] [PubMed]

41. Zhang, Y.; Liu, M.; Min, Q.; Yuan, Z.; Jing, L.I.; Fan, M. Period of organic conversion in agricultural heritage sites-Taking paddy rice of Hani terrace in Honghe county of Yunnan province as an example. J. Nat. Res. 2015, 30, 374-383, (In Chinese with English Abstract).

42. Zhang, Y.; Min, Q.; Wang, W.; He, L.; Zheng, J. Impact of household social-economic characteristics on the willingness to grow crops: A case study of jasmine growers in Fuzhou based on conservation of the agricultural heritage system. Chin. J. Eco-Agric. 2016, 24, 1714-1721, (In Chinese with English Abstract).

43. Li, Y.; Guo, J.; Li, X. Agricultural industry structure adjustment and development of rural left-behind family in minority areas: Empirical analysis based on cumulative causation theory. Lanzhou Acad. J. 2019, 9, 177-189.

44. Li, F.; Zong, X.; Shen, S. A study on the changes of old age return migrant workers' life and its impact on life satisfaction. $J$. Guizhou Provin. Party School 2019, 1, 86-94. (In Chinese)

45. Tai, Q. Tax reform, fiscal revenues, and farmers' income evidence from two waves of Chinese agricultural tax. Fudan J. Hum. Soc. Sci. 2014, 7, 265-286. [CrossRef]

46. Alhemoud, A.M.; Armstrong, E.G. Image of tourism attractions in Kuwait. J. Travel Res. 1996, 34, 76-80. [CrossRef]

47. Min, Q.W. GIAHS: A New Kind of World Heritage. Resour. Sci. 2006, 28, 206-208, (In Chinese with English Abstract).

48. Zhang, Y.; He, L.; Li, X.; Zhang, C.; Qian, C.; Li, J.; Zhang, A. Why are the Longji Terraces in southwest China maintained well? A conservation mechanism for agricultural landscapes based on agricultural multi-functions developed by multi-stakeholders. Land Use Policy 2019, 85, 42-51. [CrossRef]

49. Lennox, E.; Gowdy, J. Ecosystem governance in a highland village in Peru: Facing the challenges of globalization and climate change. Ecosyst. Serv. 2014, 10, 155-163. [CrossRef]

50. Fukamachi, K. Building resilient socio-ecological systems in Japan: Satoyama examples from Shiga Prefecture. Ecosyst. Serv. 2020, 46, 101187. [CrossRef]

51. Wang, L.; Lin, Q. An economic interpretation of wasted cultivation and rural land circulation-The pursuit of system for peasants' land rights and interests. J. Fujian Agric. For. Univ. 2010, 13, 28-31, (In Chinese with English Abstract).

52. Xia, Z.P. An acquaintance society or A semi-acquaitance one? J. Northwest. AF Univ. Soc. Sci. Ed. 2010, 10, 86-89.

53. Zhou, C.; Yang, G. The costs and benefits of citizenization of Guangdong rural-to-urban migrants and its sharing mechanism. South China Popul. 2015, 30, 20-31, (In Chinese with English Abstract).

54. Zhu, M.; Yang, Y. Recent trends in employment structure for migrant workers in China. Popul. Res. 2017, 41, 89-100, (In Chinese with English Abstract).

55. Jin, X.; Hu, Z.; Gu, D. Who are "aged" migrant workers-Data analysis based on floating population monitoring survey. Manag. Rev. 2018, 30, 271-280. 
56. He, X.; Yin, Z. The small-scale peasant economy and path selection of agricultural modernization: A review of the agricultural modernization radicalism. China Rev. Polit. Econo. 2015, 6, 45-65.

57. Yang, H. The characteristics of Chinese socialist small-scale peasant economy. Issues Agric. Econ. 2016, 37, 60-73. (In Chinese)

58. Liu, J.; Liu, D.; Zhuang, Z.; Zhang, X. Study on spatial pattern of land-use change in China during 1995-2000. Sci. China Ser. D Earth Sci. 2003, 46, 373-384.

59. Zhu, Q. The village industry in the background of rural revitalization: A sociological explanation of industry prosperity. J. China Agri. Univ. 2018, 35, 89-95.

60. Wang, X. Industry convergence: New concept of agriculture industrialization. Res. Agric. Modern. $2007,3,303-306$.

61. Luo, X.; Tian, D.; Yang, X. Rural transition of outflow village under the rapid urbanization: An empirical study on the middle Shanxi Province. Sci. Geogr. Sin. 2012, 32, 1209-1213. (In Chinese)

62. Wang, X.; Luo, R.; Zhang, L.; Rozelle, S. The education gap of China's migrant children and rural counterparts. J. Develop. Stud. 2017, 11, 1-17. [CrossRef]

63. Zhang, Y.; Min, Q.; Xu, M.; Li, X. The evaluation of industrial integration level of important agricultural heritage sites: A case study of Yunnan Honghe Hani rice terraces. J. Nat. Res. 2019, 34, 116-127, (In Chinese with English Abstract). 